\title{
SPL36 Encodes a Receptor-like Protein Kinase that Regulates Programmed Cell Death and Defense Responses in Rice
}

\author{
R. A. O. Yuchun ${ }^{1 * \dagger}$, J. I. A. O. Ran ${ }^{1 \dagger}$, W. A. N. G. Sheng ${ }^{1 \dagger}$, W. U. Xianmei ${ }^{2}$, Y. E. Hanfei ${ }^{1}$, P. A. N. Chenyang ${ }^{1}$, \\ L. I. Sanfeng ${ }^{2}$, Xin Dedong', Z. H. O. U. Weiyong ${ }^{3}$, D. A. I. Gaoxing ${ }^{3}$, H. U. Juan' ${ }^{1}$, R. E. N. Deyong ${ }^{2 *}$ and \\ W. A. N. G. Yuexing ${ }^{2^{*}}$
}

\begin{abstract}
Lesion mimic mutants spontaneously produce disease spots in the absence of biotic or abiotic stresses. Analyzing lesion mimic mutants' sheds light on the mechanisms underlying programmed cell death and defense-related responses in plants. Here, we isolated and characterized the rice (Oryza sativa) spotted leaf 36 (sp/36) mutant, which was identified from an ethyl methanesulfonate-mutagenized japonica cultivar Yundao population. sp/36 displayed spontaneous cell death and enhanced resistance to rice bacterial pathogens. Gene expression analysis suggested that sp/36 functions in the disease response by upregulating the expression of defense-related genes. Physiological and biochemical experiments indicated that more cell death occurred in sp/36 than the wild type and that plant growth and development were affected in this mutant. We isolated SPL36 by map-based cloning. A single base substitution was detected in sp/36, which results in a cysteine-to-arginine substitution in SPL36. SPL36 is predicted to encode a receptor-like protein kinase containing leucine-rich domains that may be involved in stress responses in rice. sp/36 was more sensitive to salt stress than the wild type, suggesting that SPL36 also negatively regulates the salt-stress response. These findings suggest that SPL36 regulates the disease resistance response in rice by affecting the expression of defense- and stress-related genes.
\end{abstract}

Keywords: Defense response, Receptor-like protein kinase, Lesion mimic mutant, Rice, Salt resistance, SPL36

\section{Background}

The lesion mimic phenotype is characterized by the spontaneous production of disease spots of various sizes and shapes on the leaves and leaf sheaths (and even stalks and seeds) in the absence of abiotic or biotic stress. Lesion mimics are the result of apoptosis caused by the hypersensitive response (HR) (Petrov et al., 2015).

\footnotetext{
*Correspondence: ryc1984@163.com; rendeyong616@163.com; wangyuexing@caas.cn

${ }^{\dagger}$ R. A. O. Yuchun, J. I. A. O. Ran and W. A. N. G. Sheng contributed equally to this work.

'Zhejiang Provincial Key Laboratory of Biotechnology on Specialty Economic Plants, Zhejiang Normal University, Jinhua 321004, China

${ }^{2}$ State Key Laboratory of Rice Biology, China National Rice Research Institute, Hangzhou 310006, China

Full list of author information is available at the end of the article
}

Lesion mimic mutants in rice can be divided into the initial (local) type and the spreading type based on phenotype and whether a dominant or recessive mutation is present. The first lesion mimic mutant in plants was reported in maize by the American scientist R. A. Emerson in the 1920s (Lu et al., 2012). Sekiguchi Lesion (sl), the first lesion mimic mutant identified in rice, was discovered by the Japanese scientist Sekiguchi in the mid-1960s as a naturally occurring mutant (Liu et al., 2004).

The mechanism underlying the generation of lesion mimics is complex and regulated by multiple factors, including both internal and external factors. Internal factors include the altered expression of disease resistancerelated genes, uncontrolled programmed cell death (PCD), metabolic disorders, defense signaling molecules, 
and the loss of protease function; external factors include temperature and light. For example, SPL7, the first lesion mimic mutant gene successfully cloned in rice, encodes the heat shock protein HSFA4, a transcription factor that plays a negative role in the apoptosis pathway (Yamanouchi et al., 2002). SPL7 is highly similar to maize $H S F b$, tomato $H S F 8$, and Arabidopsis $H S F 21$ and $H S F 1$, all of which regulate apoptosis in plants; mutants of these genes show lesion mimic characteristics. The phenotype of spl18 mutant of rice is associated with the insertion of a T-DNA activation tag that enhances the expression of genes around the insertion site (Mori et al., 2007). OsATL, encoding an acyltransferase homo$\log$ that induces allergic reactions to tobacco, is located $\sim 500$ bp downstream of the inserted T-DNA activation tag. This gene is expressed at low levels in wild-type rice but at high levels in spl18, resulting in the occurrence of lesion mimics due to the abnormal expression of disease resistance genes.

Rice plants with mutations in NLS1, encoding a CCNB-LRR protein, accumulate large amounts of $\mathrm{H}_{2} \mathrm{O}_{2}$ and salicylic acid and show abnormal expression of resistance-related genes, leading to the appearance of lesion mimics in leaf sheaths (Tang et al., 2011). The protein that is altered in the lesion mimic mutant spl11 contains U-box and ARM (armadillo) repeat domains and undergoes ubiquitination and protein-protein interactions when expressed in yeast and mammalian systems (Zeng et al., 2002). The similarity of this protein to other plant U-box-ARM proteins is mainly limited to the Ubox and ARM repeat regions. A single base substitution was detected in the mutant spl11 gene, resulting in the premature termination of translation of the encoded proteins. The E3 ubiquitin ligase activity of this protein is dependent on the presence of an intact U-box domain, indicating that ubiquitination plays a role in plant cell death and defense and suggesting that spontaneously formed lesion mimics are associated with uncontrolled PCD (Zeng et al., 2004). OsSSI2 encodes fatty acid dehydrogenase (FAD), which also plays a negative role in the defense response in rice. The loss of function of FAD results in lesion mimics and delayed leaf growth (Jiang et al., 2009). Mutations in a gene encoding uridine diphosphate- $\mathrm{N}$-acetylglucosamine pyrophosphorylase (UAP1), which functions during glucose metabolism, can also lead to the appearance of lesion mimics in rice leaves (Jung et al., 2005).

Most lesion mimic mutants in rice show enhanced disease resistance to some extent. Among the more than 80 mutants that have been identified, 11 mutants (including spl1, spl9, spl10, $c d r 1$, and $c d r 3$ ) show enhanced blast resistance (Liu et al., 2004; Yoshimura et al., 1997; Takahashi et al., 1999); 12 mutants (including spl21, spl24, lmes1, hm197, and hm83) show enhanced bacterial blight resistance (Wu et al., 2008); 19 mutants (including spl14, bl3, and $L m r$ ) show enhanced blast resistance and bacterial blight resistance (Mizobuchi et al., 2002); and one, $\operatorname{lmm} 1$, shows both enhanced blast resistance and sheath blight resistance. By contrast, the disease resistance of spl2, spl3, spl4, spl6, spl7, and ncrl is unchanged or even reduced compared to the wild type (Kang et al., 2007; Campbell and Ronald, 2005).

Plant receptor-like protein kinases (RLKs) occupy important metabolic positions and are abundant in plants; rice has approximately 1130 RLK genes (Nguyen et al., 2015). Plant RLKs are composed of intracellular, extracellular, and transmembrane regions (Ye et al., 2017). Most RLKs contain an extracellular receptor domain (ECLB), a transmembrane domain (TM), and a protein kinase contact response domain (PKC) (Walker, 1994; Zhang, 1998).

The leucine-rich repeat (LRR) receptor-like protein kinases are a subtype of RLKs that are involved in plant stress responses and defense-related processes, including disease responses. The $\mathrm{Cf}$ gene family of tomato leaf mold encodes proteins with LRR structures; differences in the amino acid sequences of the LRR motifs of different proteins in the same family are responsible for the specificity of ligand binding (Thomas et al., 1998). The resistance gene FLS2 in Arabidopsis has a similar structure to the sequence encoding the extracellular domain of the tomato Cf gene family (Gómez-Gómez et al., 2001). Upon binding to ligands (avirulence gene products of rice bacterial blight pathogens), the extracellular LRR structure of rice $\mathrm{Xa21}$ induces intracellular kinase phosphorylation and produces a series of cellular responses that protect the plant from pathogens (Song et al., 1995; Park and Ronald, 2012). These findings indicate that the LRR structure plays an important role in identifying the basic structures of pathogens and microorganisms.

Here, to further explore the signal transduction pathways of LRR-type receptor kinases in response to stress signals in rice, we isolated and characterized the novel lesion mimic mutant spotted leaf 36 (spl36). This mutant shows spots at the tillering stage and enhanced resistance to bacterial blight. We cloned the SPL36 gene by map-based cloning and demonstrated that it encodes a receptor-like protein kinase receptor that is expressed in all tissues and at all developmental stages after the tillering stage and is localized to the plasma membrane. A high frequency of cell death, changes in chloroplast structure, and activation of defense-related responses were observed in the spl36 mutant. We demonstrate that the loss of function of SPL36 is responsible for the cell death, premature senescence, and activation of the defense response in this mutant. 


\section{Materials and Methods}

\section{Plant Materials and Growth Conditions}

The spotted leaf mutant spl36 was isolated from a methanesulfonate (EMS)-induced mutant library of Yundao rice (wild type, WT). The mutant was hybridized with TN1 as the male parent, and the $F_{1}$ offspring and $\mathrm{F}_{2}$ population were grown in the rice experimental field of Zhejiang Normal University, Jinhua City, Zhejiang Province, China during the summer of 2018 and 2019. The F2 populations of both spl36/ZF802 and spl36/TN1 were used for genetic analysis, and the F2 recessive individuals of spl36/TN1 were used for gene fine mapping.The agronomic traits of wild-type and spl36 plants were statistically analyzed, including plant height, tiller number, grain number per panicle, seed setting rate, and 1000-grain weight. The results were analyzed based on the average of 10 replicates.

\section{Measuring Photosynthetic Parameters and Chlorophyll Content}

From 9:30 a.m.to 11:00 a.m. on sunny days, 10 individual plants with relatively uniform growth were harvested. The photosynthetic parameters of wild type and mutant plants were measured with an LI-6400XT portable photosynthesis tester. Three to five representative flag leaves were treated and measured, and each leaf was measured in triplicate (the mean value was taken as one replicate). During the measurement, red and blue light sources were used, the light intensity was constant at $1200 \mu \mathrm{mol} / \mathrm{m}^{2}$, the temperature was $30^{\circ} \mathrm{C}$, the $\mathrm{CO}_{2}$ concentration was the concentration in the air, and the humidity level was the relative humidity in the atmosphere. For chlorophyll measurements, five wild type and mutant plants with relatively uniform growth vigor were selected. The leaves were weighed, and $0.05 \mathrm{~g}$ of leaf tissue was cut into pieces and soaked in $25 \mathrm{~mL} \mathrm{1:1} \mathrm{ethanol:}$ acetone solution; three replicates were subjected to the darkening reaction for $24 \mathrm{~h}$, followed by shaking. The absorbance values at $663 \mathrm{~nm}, 645 \mathrm{~nm}$, and $470 \mathrm{~nm}$ were measured with a spectrophotometer, and the photosynthetic pigment content was calculated and statistically analyzed by Student's t-test.

\section{Preparation of Rice Protoplasts}

To generate rice protoplasts, 60 rice seedlings were cultured for 12-15 days. The leaves were removed from the plants with sterile scissors, leaving only the stalk. The material was cut into $0.5-\mathrm{mm}$ strips and placed into a sterilized $50 \mathrm{~mL}$ triangular flask. After adding $30 \mathrm{~mL} 0.6$ $\mathrm{mol} / \mathrm{L}$ mannitol, the sample was incubated for $15 \mathrm{~min}$ with shaking in the dark at $28^{\circ} \mathrm{C}$ and $50 \mathrm{r} / \mathrm{min}$. After shaking, the mannitol solution was poured off, and the sample was transferred to a clean sterile triangular flask. Enzymatic hydrolysis was performed by adding $20 \mathrm{~mL}$ enzyme solution (1.5\% fibrinase R-10, $0.75 \%$ segregation enzyme R-10, $0.6 \mathrm{~mol} / \mathrm{L}$ mannitol, $10 \mathrm{mmol} / \mathrm{L}$ MES, 10 $\mathrm{mmol} / \mathrm{L} \mathrm{CaCl}_{2}, 0.1 \% \mathrm{BSA}, \mathrm{pH} 5.7$ ) and incubating at $28^{\circ} \mathrm{C}$ with shaking at $60 \sim 80 \mathrm{R} / \mathrm{min}$ for $4 \sim 5 \mathrm{~h}$. Following enzymatic hydrolysis, the same volume of W5 solution $\left(154 \mathrm{mmol} / \mathrm{L} \mathrm{NaCl}, 125 \mathrm{mmol} / \mathrm{L} \mathrm{CaCl}_{2}, 5 \mathrm{mmol} / \mathrm{L}\right.$ $\mathrm{KCl}, 2 \mathrm{mmol} / \mathrm{L} \mathrm{MES}, \mathrm{pH} 5.7)$ was added to the sample. Pre-cooled. After $15 \mathrm{~s}$ of severe shock, the sample was passed through a nylon filter. The protoplasts were cleaned with W5 solution, centrifuged at $1000 \mathrm{r} / \mathrm{min}$ for $5 \mathrm{~min}$, and the supernatant discarded; this step was repeated 3 to 5 times. Following the addition of MMg solution, the protoplasts were collected and examined by microscopy and incubated on ice for $40 \mathrm{~min}$.

\section{Histochemical Analysis}

The content and concentration of malondialdehyde (MDA) and the enzymatic activity of superoxide dismutase of peroxidase (POD) were analyzed following the manufacturer's instructions (Nanjing Jiancheng Bioengineering Institute, Nanjing, China). The MDA and $\mathrm{H}_{2} \mathrm{O}_{2}$ contents and SOD and POD activity were measured when the tillering stage was first visible in spl36. Apoptosis was detected by TUNEL assay. FAA fixative was prepared before sampling and placed into a $2 \mathrm{~mL}$ centrifuge tube (Liang and Zhou., 2018). When the mutant lesion phenotype was apparent in spl36 leaves, leaf tissues showing this phenotype were harvested, along with wild-type leaves at the corresponding position, cut into clumps, and placed in the $2 / 3$ position of FAA fixative for fixation. The leaf tissue was vacuum infiltrated until it sank to the bottom. The tube was sealed with Parafilm and stored in a refrigerator at $4{ }^{\circ} \mathrm{C}$. A TUNEL apoptosis detection kit (Roche, Cat No.1684817) was used to measure apoptosis in the samples (Inada et al., 1998).

\section{Linkage Analysis and Mapping of sp/36}

SSR primers that are evenly distributed over the 12 rice chromosomes (from our laboratory) were used to screen the mutants and TN1 for polymorphisms (Supplementary Table 2). Twenty-one individual $F_{2}$ lesion mimic spl36/TN1 plants were used for linkage analysis to preliminarily confirm the chromosomal location of the target gene. A new InDel marker with relatively good polymorphism was developed in the mapping interval, and the target gene was precisely mapped using a single plant showing the mutant phenotype in the $\mathrm{F}_{2}$ segregating population of $s p l 36 / \mathrm{TN} 1$. Genomic DNA was extracted from the samples using the hexadecyltrimethylammonium bromide (CTAB) method (Wu et al., 2008). The PCR mixture included $1 \mu \mathrm{L}$ DNA template, $1 \mu \mathrm{L} 10 \times$ PCR buffer, $0.5 \mu \mathrm{L}$ each of forward and reverse primers $(10 \mu \mathrm{mol} / \mathrm{L})$, $1 \mu \mathrm{L}$ dNTPs, $0.2 \mu \mathrm{L}$ rTaq, and $\mathrm{H}_{2} \mathrm{O}$ to a final volume of 
$10 \mu \mathrm{L}$. The PCR amplification program was as follows: pre-denaturation at $94{ }^{\circ} \mathrm{C}$ for $4 \mathrm{~min}$; denaturation at $94{ }^{\circ} \mathrm{C}$ for $30 \mathrm{~s}$, annealing at $55-60{ }^{\circ} \mathrm{C}$ for $30 \mathrm{~s}$ (depending on the primers), extension at $72{ }^{\circ} \mathrm{C}$ for $30 \mathrm{~s}, 40$ cycles; and a final extension at $72{ }^{\circ} \mathrm{C}$ for $10 \mathrm{~min}$. The PCR products were separated by electrophoresis on a $4 \%$ agarose gel, photographed, and the data stored in a gel imager and read. The primers used for mapping are shown in Supplementary Table 3.

\section{Vector Construction}

For functional complementation of the spl36 mutants, the complete genomic DNA fragment (including the promoter) of wild-type SPL36 was amplified by PCR with primers spl36-CPT-F/ spl36-CPT-R and used to construct the vector for transformation by insertion into empty binary vector pCAMBIA1300 via Clontech InFusion PCR (TaKaRa). The full-length SPL36 open reading frame (ORF) was amplified with the primer pair spl36-GFP-F/spl36-GFP-R, and the coding sequence of SPL36 was inserted into binary vector pHQSN containing the $35 \mathrm{~S}$ promoter (p35S::SPL36) for subcellular localization analysis. The SPL36 promoter was introduced into the expression vector pCAMBIA1305.1, and the expression of SPL36 in rice tissues was revealed using the GUS reporter gene. GFP fluorescence was observed by confocal laser-scanning microscopy (Leica TCS SP5, Leica, Germany). The primers used for vector construction are shown in Supplementary Table 4.

\section{Inoculation Test}

Xanthomonas oryzae pv. Oryzae, Xoo (the causal agent of bacterial blight) was inoculated onto the flag leaves of wild-type Yundao and the spl36 mutant at the tillering stage using the leaf clipping method (The selected leaves should be fresh and free of disease spots and senescence). Specifically, healthy, fully unfolded rice leaves were selected, and the tip of each leaf $(\sim 1 \mathrm{~cm})$ was cut with scissors that were dipped into Xanthomonas oryzae pv. Oryzae, Xoo solution before making each cut. The phenotypes of the inoculated leaves were observed at 5 and 10 days after inoculation and the lesion length measured and photographed.

\section{Quantitative Reverse-Transcription PCR Analysis}

Leaf, root, stem, leaf sheath, panicle, and grain samples were collected from wild type and mutant plants at each stage of development. RNA was extracted from the samples using an RNAprep Pure Plant Kit (Cat No. DP441, Tiangen Biotech, Beijing, China) and amplified using a ReverTra-Plus-reverse transcription kit (Cat No.FSQ301, Toyobo, Japan) and backup for post-reverse transcription. Reverse-transcription PCR (qRT-PCR) was used to detect the expression of defense-related genes and the expression of SPL36 in tissues at each stage, with the OsActin gene used as an internal reference (GenBank accession number: NM001058705). The reaction mixtures contained $2 \mu \mathrm{L}$ cDNA template, $10 \mu \mathrm{L} 2 \times$ SYBR qPCR mix, $0.8 \mu \mathrm{L}$ each of forward and reverse primers, and $\mathrm{ddH}_{2} \mathrm{O}$ to a final volume of $20 \mu \mathrm{L}$. The reaction program was $95^{\circ} \mathrm{C}$ for $30 \mathrm{~s} ; 95^{\circ} \mathrm{C}$ for $5 \mathrm{~s}, 55^{\circ} \mathrm{C}$ for $10 \mathrm{~s}$; and $72{ }^{\circ} \mathrm{C}$ for $5 \mathrm{~s}$ for 40 cycles. Each reaction was performed in triplicate, and the relative expression levels of premature senescence-associated genes were calculated using the $2^{-\Delta \Delta C t}$ method. RT-PCR was performed using a quantitative fluorescence gene amplification instrument (qTOWER3G; Jena, Germany). Data were analyzed using SPSS 19.0 software and Excel. Student's ttest was used to analyze the significance of differences. The primers used for qRT-PCR are shown in Supplementary Table 5.

\section{Salt Stress Assay}

Plate test: Seeds were collected from wild-type Yundao and spl36 plants, washed, spread on $200 \mathrm{mM} \mathrm{NaCl} \mathrm{MS}$ medium, and cultured at $28^{\circ} \mathrm{C}$ in the light; MS medium without $\mathrm{NaCl}$ was used as a control. The assay was performed in triplicate, and the germination rates of the seeds were determined at each stage. After nine days of culture, root lengths were measured and photographed.

Salt stress assay at the seedling stage: Wild-type and mutant seedlings were grown hydroponically for approximately two weeks, and seedlings with roughly the same level of growth were selected for the assay. Wildtype and mutant seedlings were transferred to standard nutrient solution with or without $150 \mathrm{mM} \mathrm{NaCl}$ and cultured for four days. The salt-stressed seedlings were transferred to standard nutrient solution and allowed to recover for three days, followed by the detection of plant survival rates, fresh weight, conductivity, and proline content.

\section{Results}

Phenotype of the Lesion Mimic Mutant sp/36

Under normal growing conditions in the summer, spl36 leaves were not significantly different from those of the wild type before the tillering stage. At the tillering stage, the lesion mimic phenotype appeared in the leaf apex (Fig. 1a). From the tillering stage to the heading stage, these necrotic spots became more severe and gradually spread throughout the leaf (Fig. 1b). To investigate whether lesion formation is induced by light in spl36, as in most lesion mimics, we covered spl36 leaves with 2$3 \mathrm{~cm}$ aluminum foil at the tillering stage and used uncovered mutant leaves as controls. After seven days, no spread of lesion mimics had occurred in the covered areas of leaves, whereas lesion mimics appeared on uncovered control leaves (Fig. 1c). These results indicate 

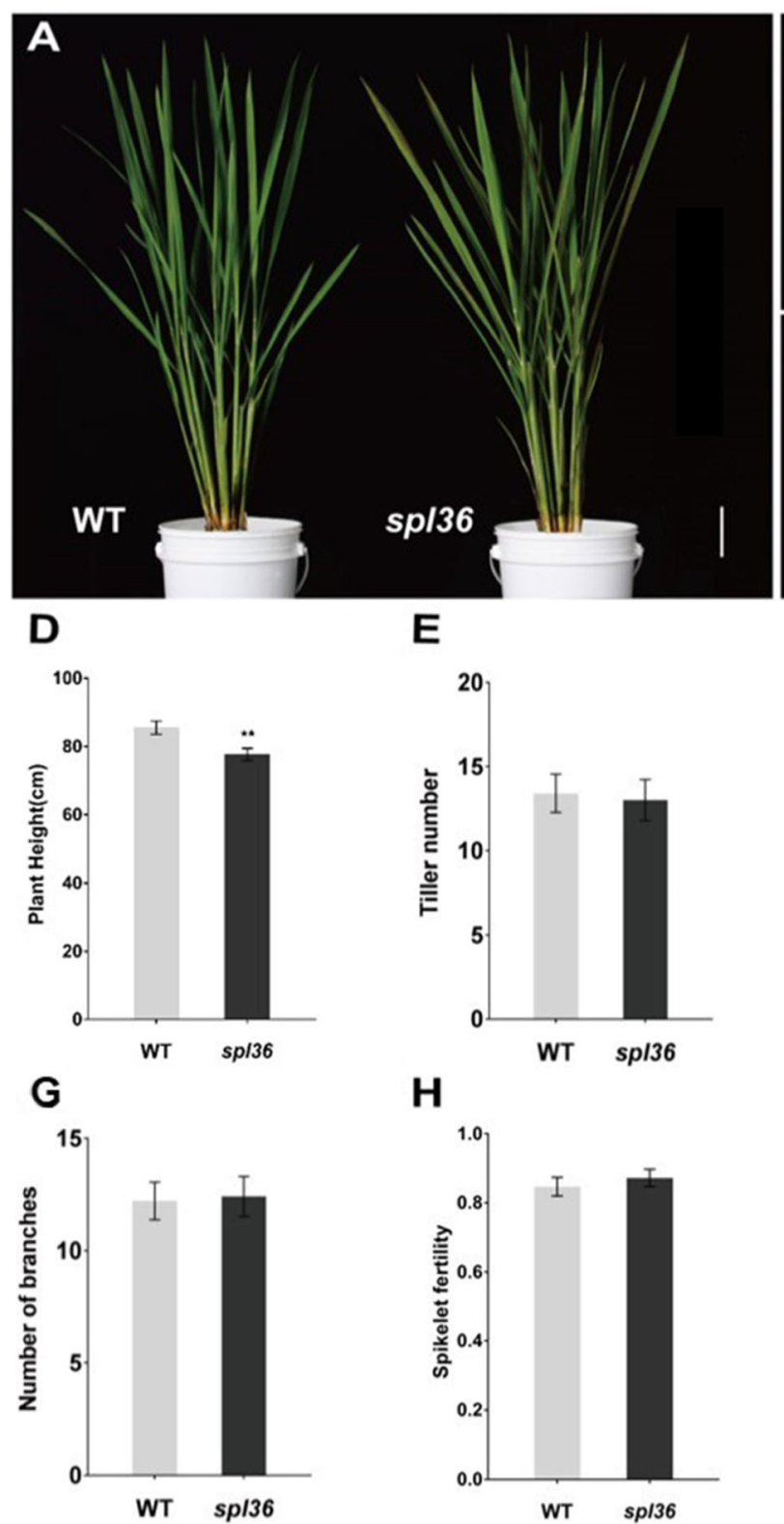

$\mathbf{E}$

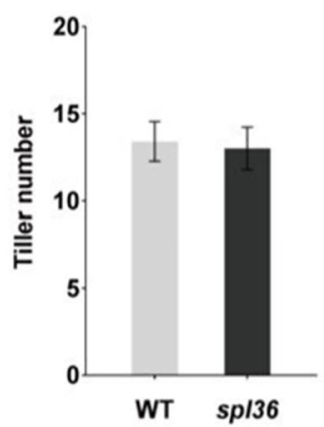

$\mathbf{H}$

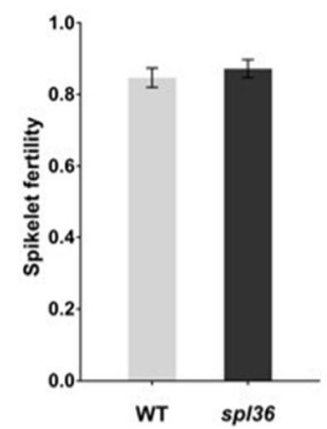

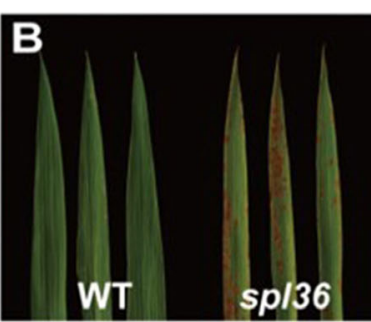

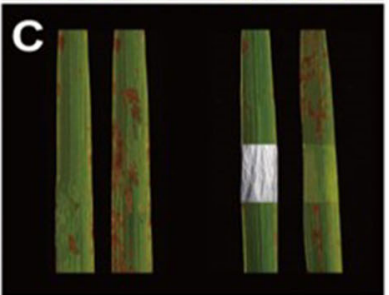

$\mathbf{F}$
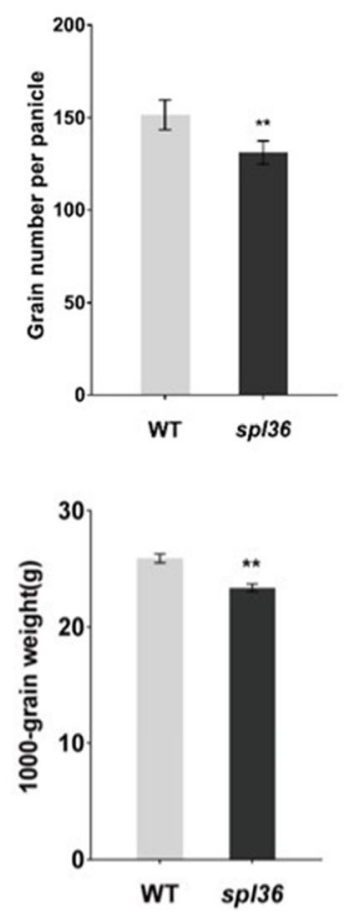

Fig. 1 Phenotypes of the sp/36 mutant. a Lesions appear at the tillering stage. Bar $=6 \mathrm{~cm}$. $\mathbf{b}$ Lesions first appear at the tip of the leaf (WT and sp/36 at the tillering stage). $\mathbf{c}$ Effect of light on lesion formation under natural conditions; sp/36 before shading $(1,2)$. sp/36 shaded for 7 days $(3,4)$. d-i Statistical analysis of important agronomic traits in WT and spl36 at the maturity stage. Values are means \pm SD $(n=10)$; ** indicates significance at $P \leq 0.01$ by Student's $t$ test

that the lesion mimic phenotype in spl36 is induced by light. In addition, the major agronomic traits, including plant height, grain number per panicle, and 1000-grain weight, were significantly reduced in spl36 vs. wild-type plants (Fig. 1d-i).

\section{SPL36 Regulates Plant Growth and Development}

Due to the negative agronomic changes in spl36, we reasoned that the growth and development of the mutant were affected after the appearance of the lesion mimics because of reduced photosynthesis (Han et al., 2015). We observed chloroplast ultrastructure by transmission electron microscopy and found that spl36 chloroplasts were atrophied and smaller than those in the WT and had disorganized lamellae (Fig. 2a-d). The contents of both chlorophyll $a$ and chlorophyll $b$ at the tillering stage were significantly reduced in spl36 compared to the wild type (Fig. 2e). In addition, the net photosynthetic rates were significantly reduced in spl36 vs. the wild type (Fig. 2g). 


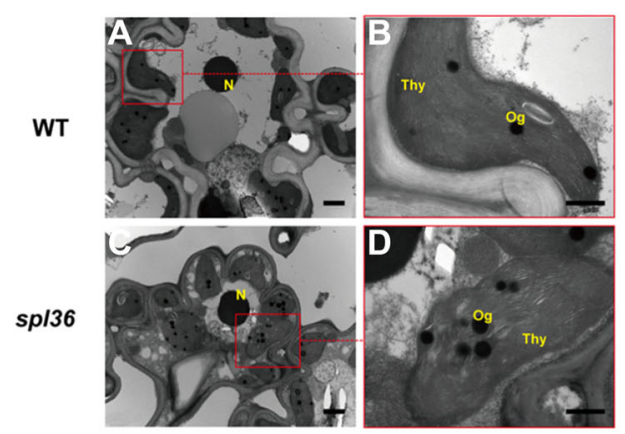

$\mathbf{F}$

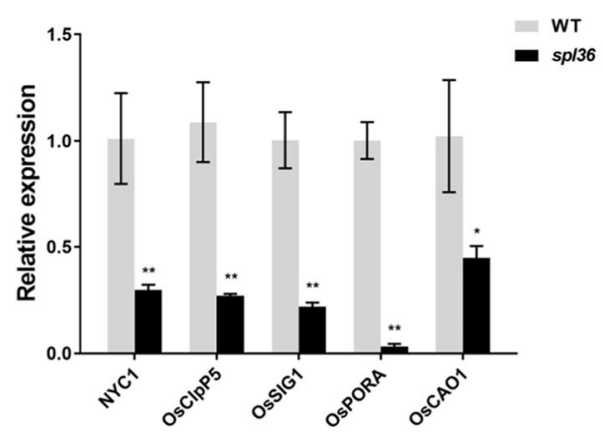

$\mathbf{E}$

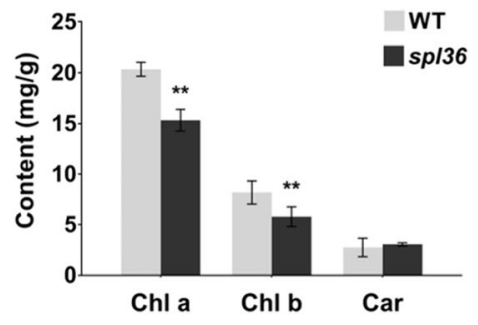

G

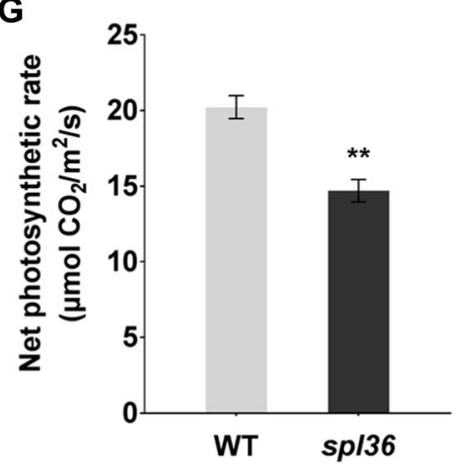

Fig. 2 Chloroplast development and net photosynthetic rate in wild-type and mutant plants. a-d Chloroplast ultrastructure in wild-type and mutant plants, a, c: leaf cells at 6000X; b, d: leaf cells at 40,000X; N: nucleus; Thy: chloroplast; Og: osmium granules; Bar = 1 mm. e Chlorophyll content in the leaves of wild-type and mutant plants at the tillering stage. $\mathbf{f}$ Relative expression of chloroplast development and pigment synthesis-related genes. $\mathbf{g}$ Net photosynthetic rate in wild-type and mutant plants at the tillering stage

To further explore the effects of the mutation on chloroplast development and chlorophyll biosynthesis, we examined the expression of chloroplast developmentand pigment synthesis-related genes in wild-type and mutant plants at the mature stage by qRT-PCR. The expression levels of NYC1, OsClpP5, OsSIG1, OsPORA, and OsCAO1 were significantly reduced in the mutant vs. the wild type (Fig. 2f). These results suggest that SPL36 influences plant growth and development via its effects on chloroplast structure.

SPL36 Regulates ROS Accumulation and Cell Death in Rice The TUNEL (terminal deoxynucleotidyl transferase dUTP nick end labeling) assay is used to detect DNA fragmentation, a marker of programmed cell death (Kim et al., 2009). The TUNEL signal in the nuclei of mutant spl36 cells was intense and randomly distributed, whereas only a weak TUNEL signal was detected in the wild type (Fig. 3a-d). In addition, the accumulation of reactive oxygen species (ROS) at high concentrations leads to an oxidative burst, which causes cell damage and even triggers programmed cell death (Kim and Coulombe, 2010). $\mathrm{H}_{2} \mathrm{O}_{2}$ contents and peroxidase (POD) activity are directly related to the accumulation of ROS. Superoxide dismutase (SOD) plays an important role in scavenging $\mathrm{O}^{2-}$ in plants. We therefore measured $\mathrm{H}_{2} \mathrm{O}_{2}$ content,
POD activity, and SOD activity in the plants and found that a large amount of $\mathrm{H}_{2} \mathrm{O}_{2}$ accumulated in spl36 (Fig. $3 e$ ), while POD and SOD activities were significantly reduced in this mutant vs. the wild type (Fig. 3g-h). The reduced activity of these enzymes negatively affects the removal of peroxide and negative oxygen ions, resulting in the accumulation of ROS. In addition, membrane lipid peroxidation occurs when plant organs age or suffer damage under stress. Malondialdehyde (MDA) is the final decomposition product of membrane lipid peroxidation, and therefore MDA content can reflect the degree of damage in stressed plants. The MDA content was significantly higher in spl36 than in the wild type (Fig. 3f). These results indicate that the lesion mimics in spl36 mutants are caused by ROS accumulation and irreversible membrane damage.

\section{SPL36 Regulates Defense Responses in Rice}

Most rice lesion mimic mutants show enhanced resistance to pathogens. To investigate whether spl36 plants showed increased resistance to rice pathogens, we performed an inoculation assay on wild-type Yundao and spl36 plants at the tillering stage and used the leaf clipping method to inoculate the plants with rice bacterial blight strain HM73. We detected changes in the inoculation site and length of the lesion mimics in the mutant 


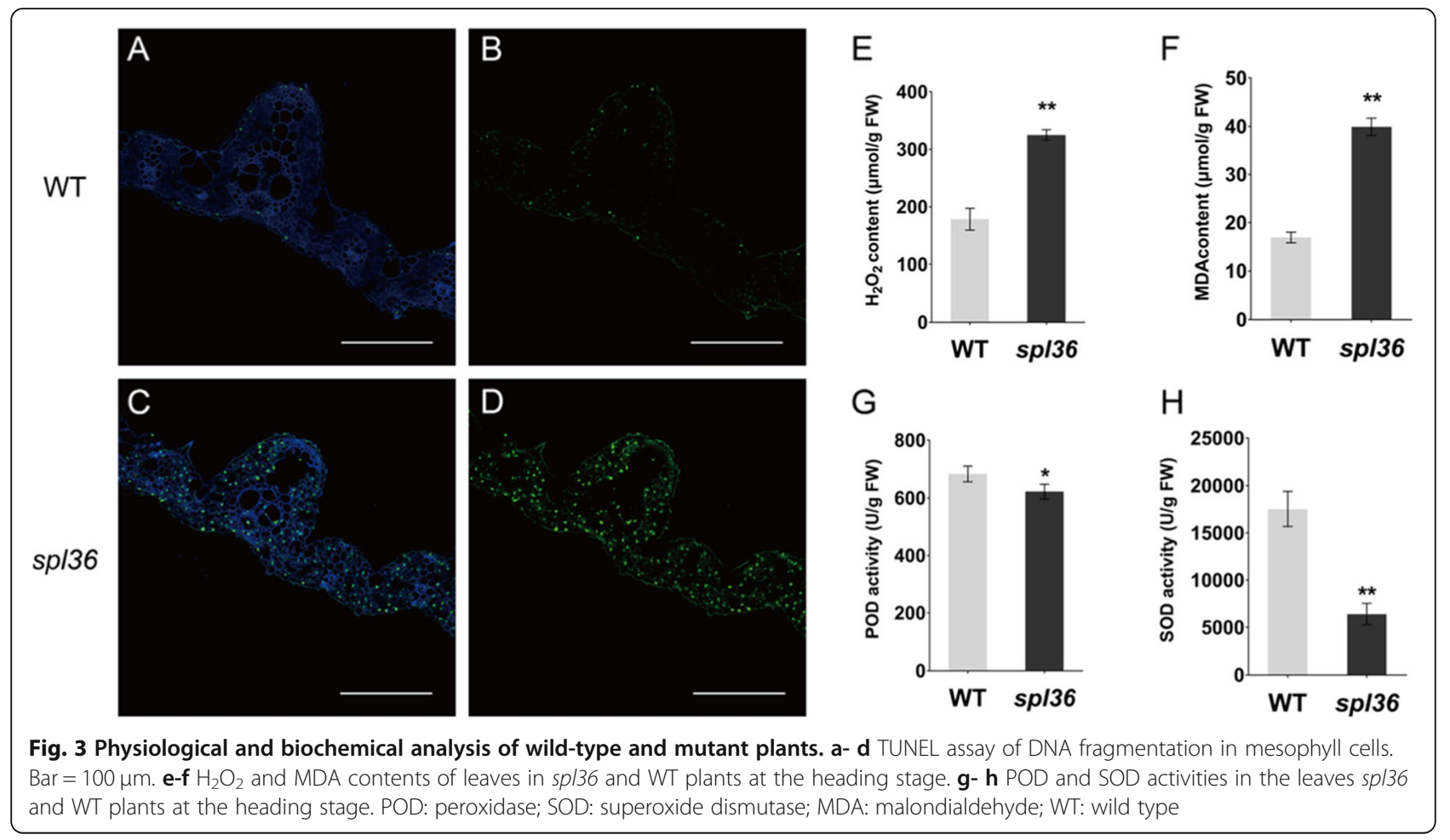

at 5 and 10 days after inoculation, respectively. At five days after inoculation, the leaf apex of the wild type showed obvious necrotic spots, whereas the mutant did not show obvious disease spots. At 10 days after inoculation, wild-type disease spots were significantly longer than those of the mutant (Fig. 4a-e). These results indicate that resistance to Xanthomonas oryzae pv. Oryzae, $X o o$ is significantly enhanced after the emergence of disease spots in spl36.

To explore the mechanism underlying the enhanced resistance of spl36 to bacterial pathogens, we examined the expression of defense-related genes in the wild type and mutants at the tillering stage by qRT-PCR. The expression levels of defense genes MAPK12, WRKY53, BIMK2, AOS2, ASP90, LYP6, PR2, PR1a, and PR1b were significantly elevated in the mutants (Fig. $4 \mathrm{f}$ ). Thus, the loss of function of the SPL36-encoded protein triggers a defense response in rice, leading to the enhanced resistance of spl36 to pathogens.

\section{Genetic Analysis and Map-Based Cloning of SPL36}

We hybridized spl36 as the female parent with ZF802 of japonica cultivar TN1. The $\mathrm{F}_{1}$ plants did not show lesion mimics. The segregation ratio of the normal phenotype to lesion mimic phenotype in the $\mathrm{F}_{2}$ population was essentially in compliance with a 3:1 ratio, indicating that the spl36 phenotype is caused by a mutation in a single recessive nuclear gene (Supplementary Table 1). We used a selection of polymorphic markers from 238 insertion and deletion tags to map the mutant gene in $21 \mathrm{~F}_{2}$ individuals with a lesion mimic phenotype and mapped the mutation site to a location between B12-5 and B12-6 on chromosome 12 (Fig. 5a). The SPL36 location was further refined to a region between JHL-3 and JHL-7 by genotyping 148 mutant F2 individuals from the same cross and adding four additional polymorphic tags (Fig. 5b). Using 554 additional $\mathrm{F}_{2}$ mutant individuals and four newly developed polymorphic tags, we ultimately mapped SPL36 to a $60 \mathrm{~kb}$ region between markers InDel1 and InDel2 (Fig. 5c). Analysis using https://rice.plantbiology.msu.edu/ predicted that this region contains 11 open reading frames (ORFs) encoding seven expressed proteins and four functional proteins (Fig. 5d). Sequencing and alignment revealed that in spl36, gene LOC_Os12g08180 was mutated (Fig. 5e): nucleotide $\mathrm{T}$ at position 1462 in the coding region of this gene was replaced by $\mathrm{C}$ (Fig. $5 \mathrm{f}$ ), resulting in the change of the encoded amino acid from cysteine to arginine (Fig. 5g). Therefore, LOC_Os12g08180 is the candidate gene for SPL36.

\section{Functional Complementation of the sp/36 Mutant with LOC_Os12g08180}

To determine whether the single base substitution in LOC_Os12g08180 is indeed associated with the spl36 phenotype, we constructed the vector $p G S P L 36$, which contained genomic DNA fragments including the promoter of the SPL36 gene in wild-type Yundao, and 

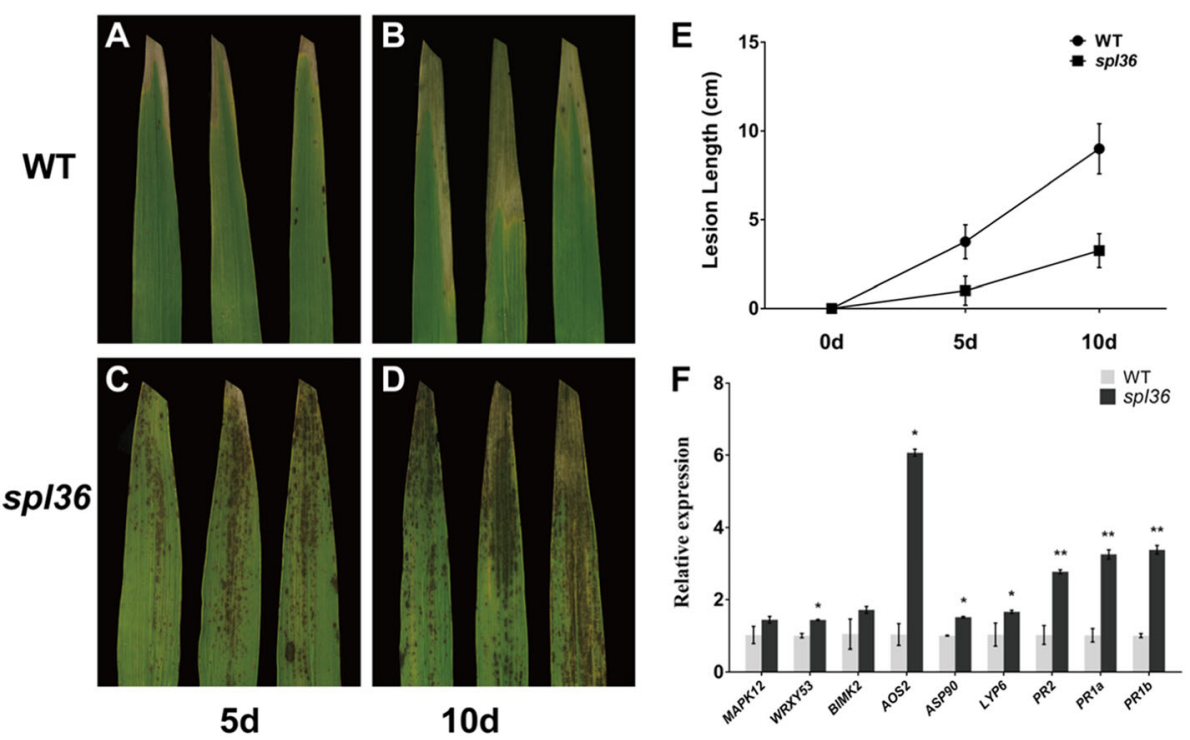

Fig. 4 SPL36 regulates defense responses in rice. a-d Phenotypes of wild-type and sp/36 leaves at 5 days and 10 days after inoculation with the bacterial blight pathogen HM73. e Statistical analysis of the length of bacterial leaf blight lesions. $\mathbf{f}$ Relative expression of defense-related genes in uninoculated plants

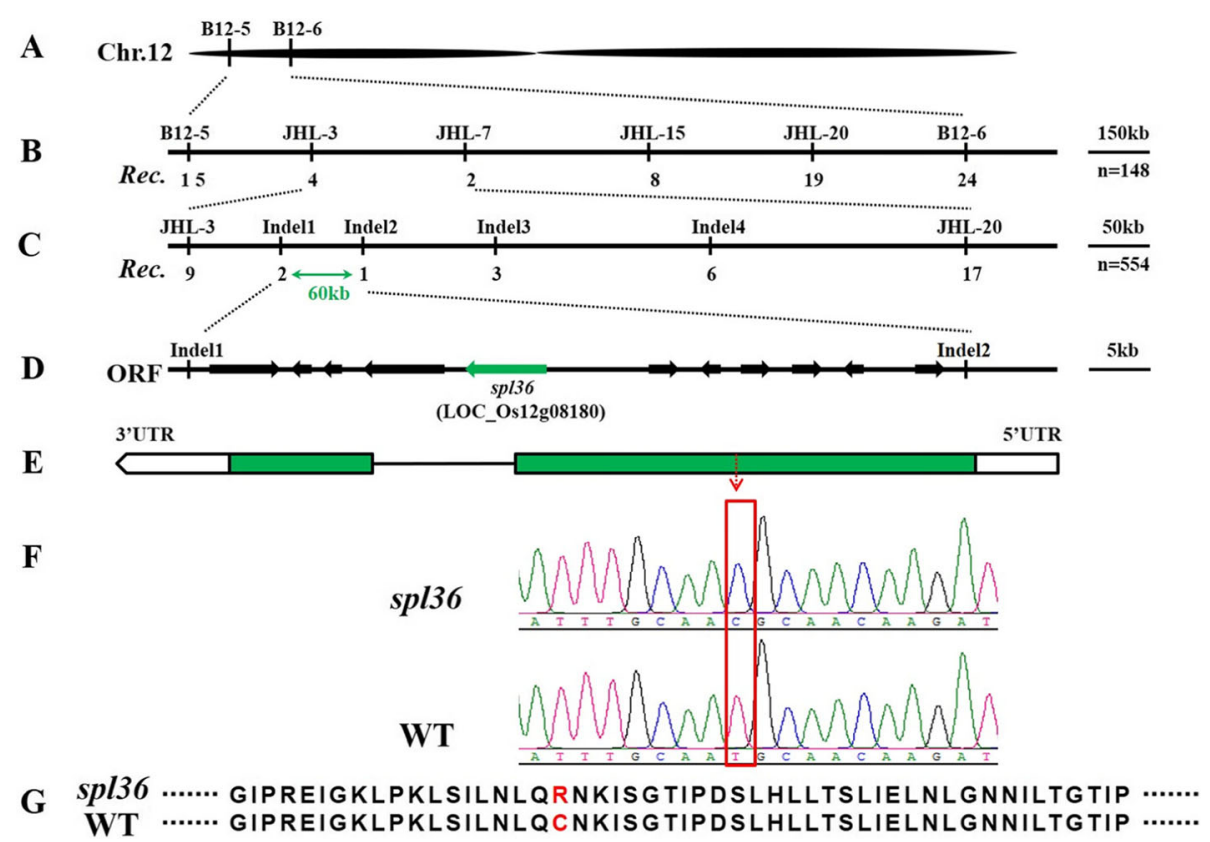

Fig. 5 Genetic and physical maps of the SPL36 gene. a The SPL36 gene was localized to chromosome 12 between InDel markers B12-5 and B12-6. b The SPL36 gene was delimited to the JHL-3 to JHL-7 interval on chromosome 12 using $148 \mathrm{~F}_{2}$ mutant individuals; marker names and number of recombinants (Rec.) are shown. C Fine genetic mapping of the SPL36 gene based on 554 mutant $F_{2}$ individuals. d 11 putative ORFs located in the $\sim 60-\mathrm{kb}$ region of this locus. e Gene structure of LOC_Os12g08180. f Sequence analysis of the T-to-C mutation site in wild type and sp/36. $\mathbf{g}$ The mutation results in a change from cysteine to arginine in the encoded protein 
introduced it into spl36 by Agrobacterium tumefaciensmediated transformation. The corresponding empty vector $\mathrm{pEmV}$ was used as a control. Of the $60 \mathrm{~T} 0$ plants, 54 were positive transformants. All of these transformants had the same phenotype as the wild type (Fig. 6a), while plants transformed with the control vector showed the same lesion mimic phenotype as spl36 (Fig. 6b). These results demonstrate that LOC_Os12g08180 is SPL36 and that the single base substitution in spl36 leads to the appearance of the lesion mimic phenotype of the mutant.

\section{Expression Analysis of SPL36}

We performed reverse-transcription quantitative PCR (qRT-PCR) to analyze the expression of SPL36 in various organs. SPL36 was expressed in all organs, with higher expression levels in leaves, leaf sheaths, and roots and lower expression levels in stems and panicles. SPL36 was expressed at significantly higher levels in all organs of spl36 compared to wild-type Yundao (Fig. 7a). To analyze the spatiotemporal expression pattern of SPL36 more precisely, we constructed the vector pSPL36::GUS by fusing the GUS gene with the promoter of SPL36 from the wild type. We then performed Agrobacterium tumefaciens-mediated transformation to obtain transgenic plants. We stained various organs of the transgene-positive plants and observed GUS signal in various tissues (Fig. 7b-f). Our results showed that SPL36 was expressed in tested organs and tissues including the root, leaf, leaf sheath, stem and panicle. Notably, SPL36 transcript level was more abundant in the leaf relative to other tissues or organs. Relative strong GUS signals were observed in the leaf, whereas weak signals were also found in the root, culm, leaf sheath, and panicle. These findings were consistent with the RT-qPCR results.

\section{Subcellular Localization of SPL36}

To determine the subcellular location of SPL36, we fused the full-length coding sequence of SPL36 to the N- terminus of green fluorescent protein (GFP). When transiently expressed in rice protoplasts, the GFP signal appeared on the plasma membrane and cytoplasm and the signal of 35S::GFP appeared on membrane, cytoplasm, and nucleus (Fig. 8a-d). To verify this observation, we transformed Nicotiana benthamiana leaves with a plasmid containing the SPL36-GFP fusion vector. SPL36GFP protein was detected on the membrane and cytoplasm and 35S::GFP protein was detected on the membrane, cytoplasm, and nucleus (Fig. 8e-h). These results indicate that SPL36 localizes to the membrane and cytoplasm.

\section{SPL36 Is Involved in Salt Stress Responses in Rice}

After verifying that the single base substitution of $L O C_{-}$ Os12g08180 was responsible for the lesion mimic phenotype of spl36, we determined that this gene encodes a receptor-like protein kinase. Plant receptor-like protein kinases play regulatory roles in plant growth and development and disease resistance (Afzal et al., 2008; Li Liyun et al., 2008), and most of them function in stress responses. To investigate whether SPL36 is involved in stress response-related pathways, we performed salt stress assays in which we placed wild-type and mutant seeds in flat dishes for the germination assay and grew seedlings hydroponically in the absence and presence of $\mathrm{NaCl}$ for the seedling assay.

In the absence of salt treatment, no significant difference in the germination rates of spl36 vs. wild-type seeds was detected over a one-week period. Under salt treatment, the germination rates of both mutant and wildtype seeds decreased significantly, while the germination rate of the wild type was also significantly lower than that of the mutant. After 9 days of culture in the germination assay, we measured the lengths of the root portions of salt-treated and control seedlings. Under control conditions, there was no significant difference in stem length between wild-type and mutant seedlings. By contrast, under $\mathrm{NaCl}$ treatment, the stems were significantly
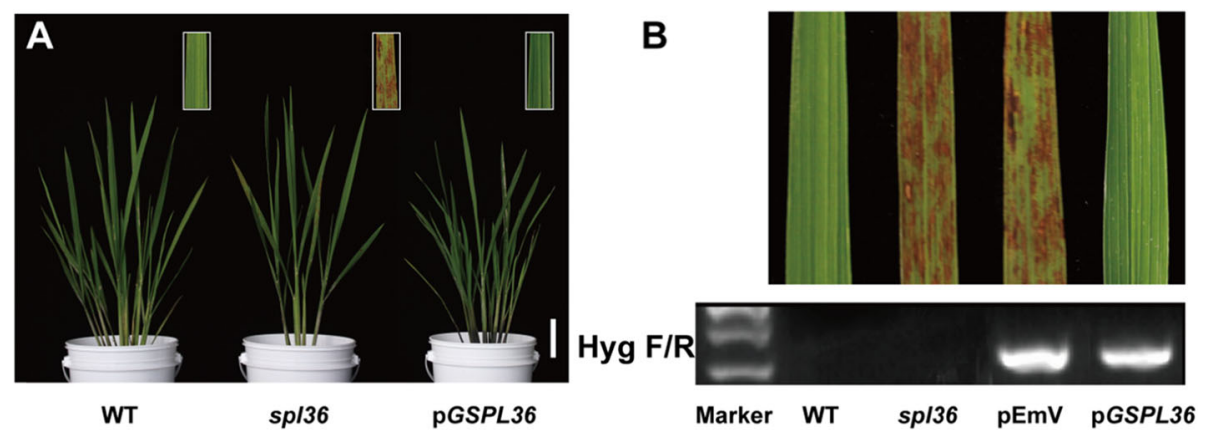

Fig. 6 Functional complementation of the spl36 mutant with LOC_Os12g08180. a The phenotype of the sp/36 mutant transformed with the genomic sequence of SPL36 (pGSPL36) was completely recovered to that of the wild type. The insets show enlarged views of leaf sections with lesion spots. Bar $=8 \mathrm{~cm}$. b Transgenic plants were verified by the presence of the hygromycin selectable marker gene. pEmV: empty vector 

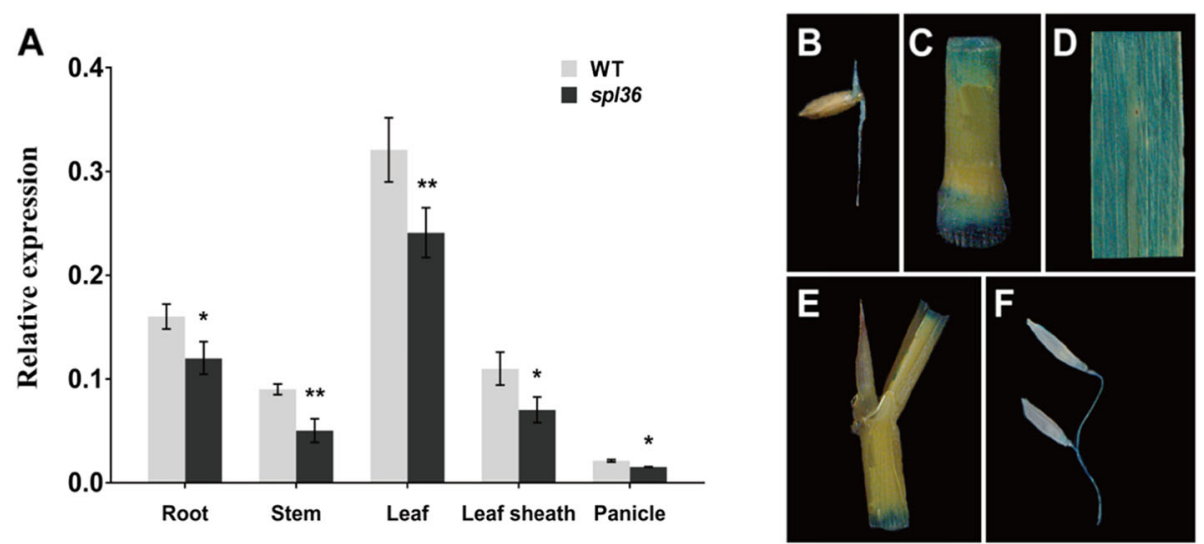

Fig. 7 Expression analysis of SPL36. a Expression of SPL36 in various organs of wild type and sp/36 plants analyzed by quantitative RT-PCR. b-f Histochemical signals from the SPL36 promoter-GUS reporter gene. GUS signals were detected in the root $\mathbf{b}$, stem $\mathbf{c}$, leaf $\mathbf{d}$, leaf sheath $\mathbf{e}$, and panicle $\mathbf{f}$
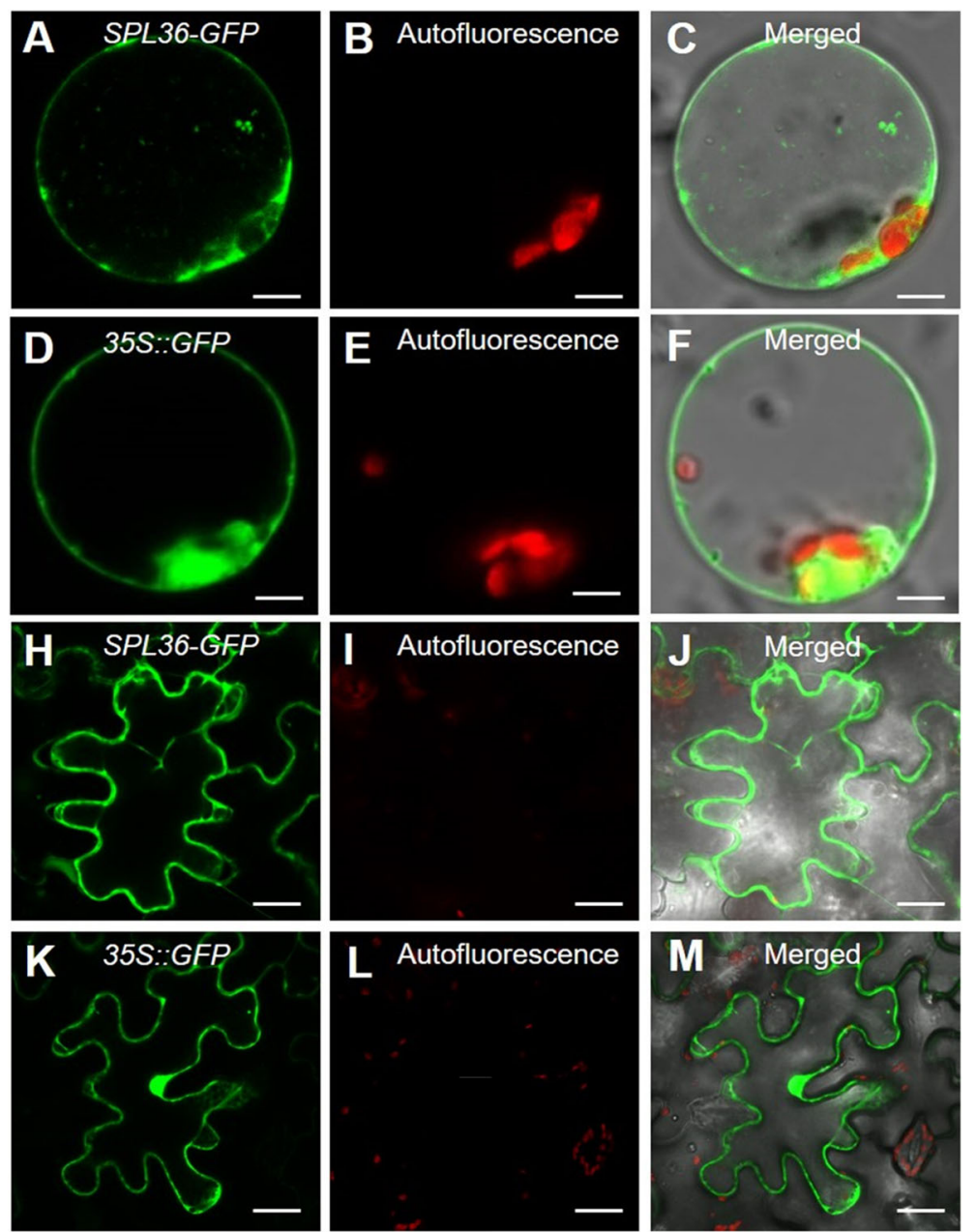

Fig. 8 Subcellular localization of SPL36. a-c Transient assay in rice protoplasts. $\mathbf{h}-\mathbf{j}$ N. benthamiana leaf assay. $\mathbf{d}-\mathbf{f}$ and $\mathbf{k}-\mathbf{m}$ 35S.::GFP controls used in the assays. SPL36-GFP: SPL36 GFP fusion protein. Bar $=20 \mu \mathrm{m}$ 
shorter in mutant vs. wild-type seedlings (Supplementary Fig. 1). We also grew wild-type and mutant seedlings hydroponically for four weeks, cultured them in highsalt medium for four days, returned them to normal conditions for recovery, and examined them three days later. No significant changes were detected in the wild type following four days of treatment, with the phenotype recovering after the return to normal conditions. By contrast, while spl36 showed significant leaf bending after salt treatment, and the plants did not recover or even died following their return to normal conditions. Our analysis of fresh weight, conductivity, and final survival of plants before and after treatment and under control conditions revealed that spl36 was more sensitive to salt treatment than the wild type (Fig. 9). In summary, SPL36 is involved in salt-stress responses in rice.

\section{Discussion}

Lesion mimic mutants are extremely valuable for studying PCD and defense-related responses in plant cells. In the present study, we selected the lesion mimic mutant spl36 from a mutant library generated by mutagenizing wild-type Yundao rice using EMS. There were no obvious phenotypic differences between this mutant and the wild type at the seedling stage. However, reddish-brown disease spots appeared in the mutant at the leaf apex at the tillering stage and gradually spread throughout the leaf. We observed the chloroplast ultrastructures of both the wild type and mutant at this stage and measured their photosynthetic rates. The appearance of lesion mimics led to significant changes in chloroplast structure in the mutant. Since chloroplasts are the sites of photosynthesis (Wu et al., 2018), the appearance of lesion mimics affected both the growth and development of the plants. Altered chloroplast structure is also a direct cause of the decline in multiple agronomic traits in plants (Ishikawa et al., 2001).

Using map-based cloning, we mapped the SPL36 gene within a $60 \mathrm{~Kb}$ interval on chromosome 12 . Based on information in the rice genome database (https://rice. plantbiology.msu.edu/), this interval contains 11 ORFs, including genes for seven expressed proteins and four functional proteins. We amplified the genomic sequences in this region in the mutant and wild type by PCR. Sequence alignment and sequencing analysis revealed that nucleotide $\mathrm{T}$ at position 1462 in the coding region of the gene LOC_Os12g08180 was replaced with $\mathrm{C}$, resulting in a change in the encoded amino acid from cysteine to arginine. Using a functional complementation assay, we determined that this gene is SPL36.
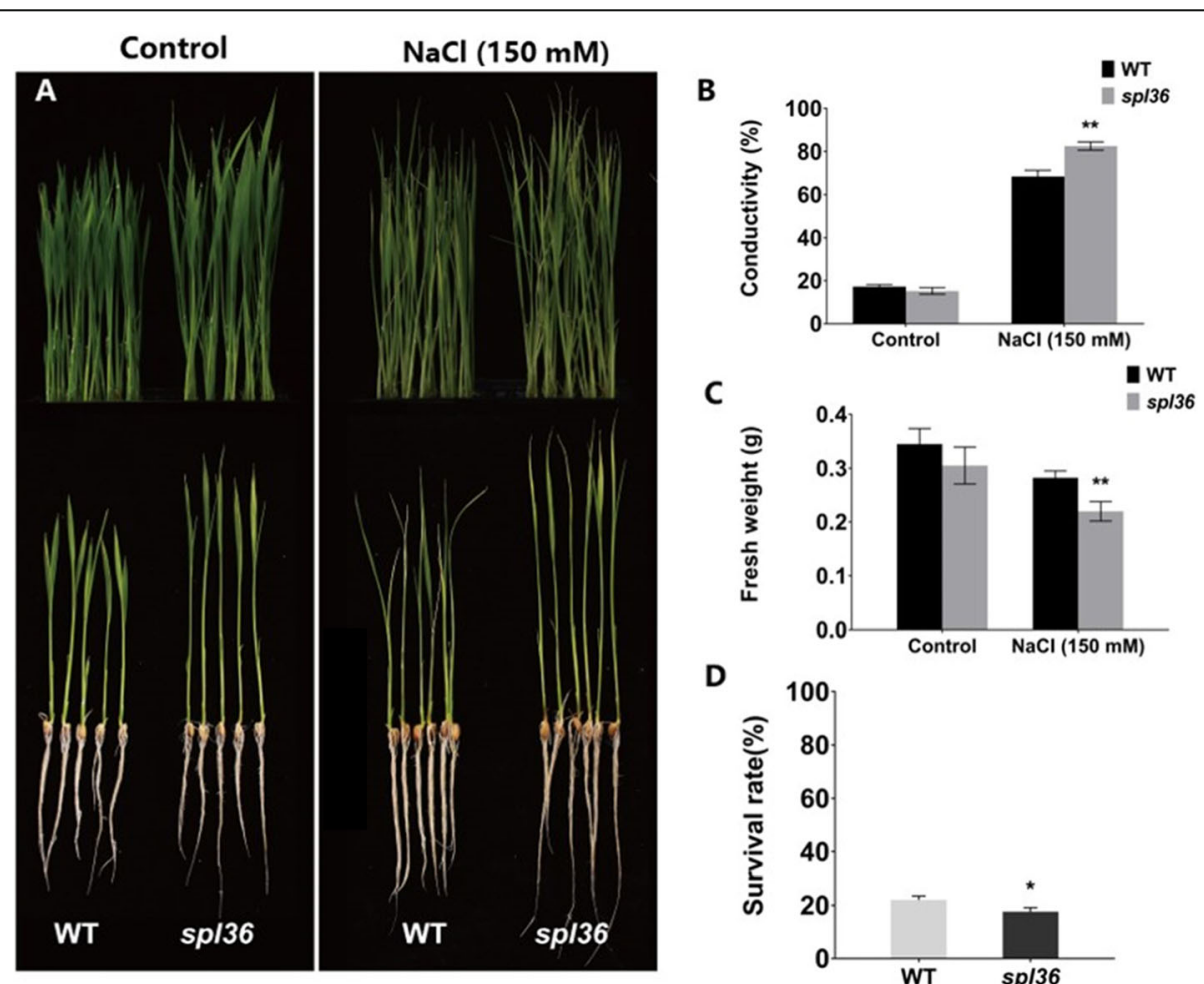

C

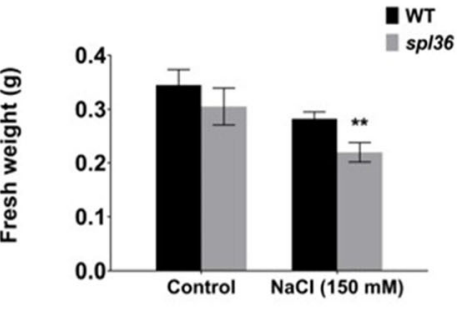

D

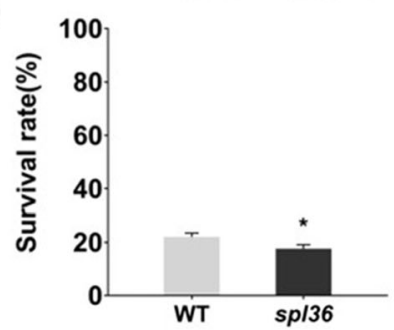

Fig. 9 Analysis of salt-stress responses in wild type and spl36 plants at the seedling stage. a Phenotypes wild-type and mutant seedlings before and after $150 \mathrm{mM} \mathrm{NaCl}$ treatment. b Conductivity of wild-type and mutant seedlings before and after $150 \mathrm{mM} \mathrm{NaCl}$ treatment. c Fresh weights of wild-type and mutant seedlings before and after $150 \mathrm{mM} \mathrm{NaCl}$ treatment. $\mathbf{d}$ Survival rates of wild-type and mutant seedlings after 150 mM $\mathrm{NaCl}$ treatment 
Structural analysis of the protein encoded by this gene showed that this protein is a receptor-like protein kinase receptor containing multiple leucine-repeat domains (Supplementary Fig. 2).

Leucine-rich receptor-like kinases (LRR-RLKs) are closely related to stress and defense responses in plants. The PRK1 gene was initially isolated from Arabidopsis in 1997 by Hong et al. (Hong et al., 1997), who demonstrated that the LRR domain of PRK1 functions in protein-protein interactions, as well as the perception of stress signals from the environment. In 2014, Yang et al. (Yang et al., 2014) identified new LRR-RLKs in wild soybean and demonstrated that GsLRPK improves drought resistance when exogenously expressed in Arabidopsis. OsGIRL1 is upregulated in response to abiotic stresses including salt, osmotic stress, and heat, and the stressrelated hormones salicylic acid and abscisic acid but is downregulated in response to jasmonic acid; OsGIRL1 is located in the plasma membrane. The biological function of OsGIRL1 was explored by exogenously expressing this gene in Arabidopsis plants and examining plant responses to irradiation, salt pressure, osmotic pressure, and thermal stress (Park et al., 2014). The LRR type receptor protein kinase gene OsRLK1 is induced by low temperature and salt stress in rice (Lee et al., 2004). CALRR1 in pepper is induced not only by exposure to anthrax pathogens but also under abiotic stress conditions such as high salt, abscisic acid, and wounding (Jung et al., 2004). Here, using two different salt stress protocols, we demonstrated that spl36 was more sensitive than the wild type to salt treatment. Although these results can be explained by the finding that a missense mutation in the coding region of LOC_Os $12 g 08180$ led to the loss of protein function, the specific mechanism remains to be elucidated and will be explored in the future.

LRR-RLKs are primarily associated with abiotic stress responses in plants, while their relationships with $\mathrm{PCD}$ and disease resistance have not been reported. We verified the higher frequency of cell death in spl36 by performing a TUNEL assay and measured $\mathrm{H}_{2} \mathrm{O}_{2}$ and MDA levels and POD and SOD activities in the wild type and mutant. spl36 accumulated more ROS than the wild type, which led to an oxidative burst and ultimately PCD. Since lesion mimics arise spontaneously in spl36, our findings indicate that SPL36 negatively regulates $\mathrm{PCD}$ in rice.

Most previously reported lesion mimic mutants show some enhancement of disease resistance. To investigate whether SPL36 is involved in disease resistance in rice, we used the leaf clipping method to inoculate wild-type and mutant plants with the bacterial blight pathogen HM73 and found that spl36 had significant resistance to this pathogen. However, it remains to be determined whether spl36 has broad-spectrum resistance. We also analyzed the expression of several defense-related genes in the wild type and mutant. The defense genes MAPK12, WRKY53, BIMK2, AOS2, LYP6, PR1a, and $P R 1 b$ were significantly upregulated in the mutant vs. the wild type. OsWRKY53 encodes a transcriptional activator that plays an important role in the excitationinduced defense signal transduction pathway in rice (Chujo et al., 2007; Tian et al., 2017). OsAOS2 expression in leaves is significantly induced by rice blast. The expression of OsAOS2 driven by the PBZ1 promoter activated the expression of other pathogenesis-related genes, thereby increasing resistance to rice blast (Mei et al., 2006). OsBIMK2 plays an important role in rice disease resistance responses (Song et al., 2006). LYP6 encodes a protein containing cytolytic enzyme motifs that functions as a pattern recognition receptor for bacterial peptidoglycan and fungal chitin and plays a dual role in the recognition of peptidoglycan and chitin during innate immunity in rice (Liu et al., 2012). OsPR1a and $O s P R 1 b$ are pathogenesis-related genes (Agrawal et al., 2000). Based on our results, we propose that SPL36 regulates the disease resistance response in rice by upregulating the expression of defense genes, but the specific mechanism requires further investigation.

\section{Conclusion}

We cloned a novel spotted leaf gene (SPL36) encoding a receptor-like protein kinase that contains repeated leucine domains and may be involved in stress responses in rice. This is the first report of the involvement of a receptor-like protein kinase in disease resistance-related pathways in rice. We demonstrated that the loss of function of SPL36 results in enhanced resistance to pathogens and increased salt sensitivity. We are currently conducting an in-depth study to determine whether the spl36 mutant has broad-spectrum resistance to pathogens and to uncover the role of SPL36 in the salt stress response in rice.

\section{Abbreviations \\ EMS: Ethyl methyl sulfonate; GFP: Green fluorescent protein; GUS: $\beta$ - glucuronidase; LRR-RLK: Leucine-rich repeat receptor-like protein kinase; PCR: Polymerase chain reaction; PCD: Programmed cell death; \\ POD: Peroxidase; qRT-PCR: Quantitative reverse-transcription polymerase chain reaction; QTL: Quantitative trait locus; RNA: Ribonucleic acid; ROS: Reactive oxygen species; SDS: Sodium dodecyl sulfate; SOD: Superoxide dismutase; TUNEL: Terminal-deoxynucleotidyl transferase dUTP nick end labeling}

\section{Supplementary Information}

The online version contains supplementary material available at https://doi. org/10.1186/s12284-021-00475-y.

Additional file 1: Table S1. Genetic analysis of the lesion mimic phenotype in $F_{2}$ populations. Table S2. Distribution of primers used to detect polymorphisms on each chromosome. Table S3. Primers used for 
mapping. Table S4. Primers used for vector construction. Table S5. Primers used for qRT-PCR. Figure S1. Analysis of salt stress in wild type and sp/36. A Wild-type and mutant seeds on $200 \mathrm{mM} \mathrm{NaCl}$ at 9 days of culture. B Analysis of relative germination rates of wild-type and mutant seeds after salt stress. C Analysis of growth potential in wild type and mutant seeds on $200 \mathrm{mM} \mathrm{NaCl}$ at 9 days of culture. D Analysis of stem length in wild type and mutant plants after 9 days of salt stress treatment. Figure S2. Structural prediction of the protein encoded by SPL36. A Predicted protein structure of SPL36. B Protein domains of SPL36. C Alignment of the conserved amino acid sequences of SPL36 homologs in various organisms.

\section{Acknowledgements}

Not applicable.

\section{Authors' contributions}

R. Y. C., W. Y. X., planned and designed the research; J. R., W. X. M., W. S., H. J., Y. H. F., P.C.Y., and L. H., performed the experiments; R. Y. C., W.S., and J. R. wrote the manuscript; R. Y. C., L. S. F., Z.W.Y, D.G.X., and R. D. Y. analyzed the data and edited the article. All authors read and approved the final article.

\section{Funding}

This work was supported by the National Science and Technology Major Project (2016ZX08009003-003-008), National Natural Science Foundation of China (Grant No. 31971921), Agricultural Science and Technology Innovation Program of CAAS, Key Laboratory of Rice Genetics and Breeding, Guangxi and the State Key Laboratory of Rice Biology, China (20200102).

\section{Availability of Data and Materials}

All data generated or analyzed during this study are included in this published article and its additional files.

\section{Declarations}

\section{Ethics Approval and Consent to Participate}

Not applicable.

\section{Consent for Publication}

Not applicable.

\section{Competing Interests}

Not applicable.

\section{Author details}

${ }^{1}$ Zhejiang Provincial Key Laboratory of Biotechnology on Specialty Economic Plants, Zhejiang Normal University, Jinhua 321004, China. ${ }^{2}$ State Key Laboratory of Rice Biology, China National Rice Research Institute, Hangzhou 310006, China. ${ }^{3}$ Guangxi Academy of Agricultural Sciences, Nanning 530000, China.

\section{Received: 8 December 2020 Accepted: 23 March 2021}

\section{Published online: 07 April 2021}

\section{References}

Agrawal GK, Jwa NS, Rakwal R (2000) A novel rice (Oryza sativa L.) acidic PR1 gene highly responsive to cut, phytohormones, and protein phosphatase inhibitors. Biochem Biophys Res Commun 274(1):157-165. https://doi.org/1 $0.1006 / \mathrm{bbrc} .2000 .3114$

Campbell MA, Ronald PC (2005) Characterization of four rice mutants with alterations in the defence response pathway. Mol Plant Pathol 6(1):11-21. https://doi.org/10.1111/1468-0025.00206-i1

Chujo T, Takai R, Akimoto-Tomiyama C, Ando S, Minami E, Nagamura Y, Kaku H, Shibuya N, Yasuda M, Nakashita H, Umemura K, Okada A, Okada K, Nojiri H, Yamane $H$ (2007) Involvement of the elicitor-induced gene OsWRKY53 in the expression of defense-related genes in rice. Biochim Biophys Acta 1769(7-8): 497-505. https://doi.org/10.1016/j.bbaexp.2007.04.006

Gómez-Gómez L, Bauer Z, Boller T (2001) Both the extracellular leucine-rich repeat domain and the kinase activity of FSL2 are required for flagellin binding and signaling in Arabidopsis. Plant Cell 13(5):1155-1163. https://doi. org/10.1105/tpc.13.5.1155
Han SH, Yoo SC, Lee BD, An G, Paek NC (2015) Rice FLAVIN-BINDING, KELCH REPE AT, F-BOX 1 (OsFKF1) promotes flowering independent of photoperiod. Plant Cell Environ 38(12):2527-2540. https://doi.org/10.1111/pce.12549

Hong SW, Jon JH, Kwak JM, Nam HG (1997) Identification of a receptor-like protein kinase gene rapidly induced by abscisic acid, dehydration, high salt, and cold treatments in Arabidopsis thaliana. Plant Physiol 113(4):1203-1212. https://doi.org/10.1104/pp.113.4.1203

Inada N, Sakai A, Kuroiwa H, Kuroiwa T (1998) Three-dimensional analysis of the senescence program in rice (Oryza sativa L.) coleoptiles. Investigations of tissues and cells by fluorescence microscopy. Planta 205(2):153-164. https:// doi.org/10.1007/s004250050307

Ishikawa A, Okamoto H, Iwasaki Y, Asahi T (2001) A deficiency of coproporphyrinogen III oxidase causes lesion formation in Arabidopsis. Plant J 27(2):89-99. https://doi.org/10.1046/j.1365-313x.2001.01058.x

Jiang CJ, Shimono M, Maeda S, Inoue H, Mori M, Hasegawa M, Sugano S, Takatsuji H (2009) Suppression of the rice fatty-acid desaturase gene OsSSI2 enhances resistance to blast and leaf blight diseases in rice. Mol PlantMicrobe Interact 22(7):820-829. https://doi.org/10.1094/MPMI-22-7-0820

Jung EH, Jung HW, Lee SC, Han SW, Heu S, Hwang BK (2004) Identification of a novel pathogen-induced gene encoding a leucine-rich repeat protein expressed in phloem cells of Capsicum annuum. Biochim Biophys Acta 1676(3):211-222. https://doi.org/10.1016/S0167-4781(03)00120-9

Jung YH, Lee JH, Agrawal GK, Rakwal R, Kim JA, Shim JK, Lee SK, Jeon JS, Koh HJ, Lee YH, Iwahashi H, Jwa NS (2005) The rice (Oryza sativa) blast lesion mimic mutant, blm, may confer resistance to blast pathogens by triggering multiple defense-associated signaling pathways. Plant Physiol Biochem 43(4):397-406. https://doi.org/10.1016/.jplaphy.2005.03.002

Kang SG, Matin MN, Bae H, Natarajan S (2007) Proteome analysis and characterization of phenotypes of lesion mimic mutant spotted leaf 6 in rice. Proteomics 7(14):2447-2458. https://doi.org/10.1002/pmic.200600961

Kim JA, Cho K, Singh R, Jung YH, Jeong SH, Kim SH, Lee JE, Cho YS, Agrawal GK, Rakwal R, Tamogami S, Kersten B, Jeon JS, An G, Jwa NS (2009) Rice OsACDR1 (Oryza sativa L. accelerated cell death and resistance 1 ) is a potential positive regulator of fungal disease resistance. Mol Cells 28(5):431-439. https://doi. org/10.1007/s10059-009-0161-5

Kim S, Coulombe PA (2010) Emerging role for the cytoskeleton as an organizer and regulator of translation. Nat Rev Mol Cell Biol 11(1):75-81. https://doi. org/10.1038/nrm2818

Lee SC, Kima JY, Kima SH, Kima SJ, Lee K, Hana SK, Choi HS, Jeong DH, Anb G, Kima SR (2004) Trapping and characterization of cold-responsive genes from T-DNA tagging lines in rice. Plant Sci 166(1):69-79. https://doi.org/10.1016/j. plantsci.2003.08.008

Liang XX, Zhou JM (2018) The secret of fertilization in flowering plants unveiled. Sci Bull 63:408-410

Liu B, Li JF, Ao Y, Qu J, Li Z, Su J, Zhang Y, Liu J, Feng D, Qi K, He Y, Wang J, Wang HB (2012) Lysin motif-containing proteins LYP4 and LYP6 play dual roles in peptidoglycan and chitin perception in rice innate immunity. Plant Cell 24(8):3406-3419. https://doi.org/10.1105/tpc.112.102475

Liu G, Wang L, Zhou Z, Leung H, Wang GL, He C (2004) Physical mapping of a rice lesion mimic gene, Spl1, to a 70-kb segment of rice chromosome 12. Mol Gen Genomics 272(1):108-115. https://doi.org/10.1007/s00438-004-1040-6

Lu XM, Hu XJ, Zhao YZ, Song WB, Zhang M, Chen ZL, Chen W, Dong YB, Wang ZH, Lai JS (2012) Map-based cloning of zb7 encoding an IPP and DMAPP synthase in the MEP pathway of maize. Mol Plant 5(5):1100-1112. https://doi. org $/ 10.1093 / \mathrm{mp} / \mathrm{sss} 038$

Mei C, Qi M, Sheng G, Yang Y (2006) Inducible overexpression of a rice allene oxide synthase gene increases the endogenous jasmonic acid level, PR gene expression, and host resistance to fungal infection. Mol Plant-Microbe Interact 19(10):1127-1137. https://doi.org/10.1094/MPMI-19-1127

Mizobuchi R, Hirabayashi H, Kaji R, Nishizawa Y, Satoh H, Ogawa T, Okamoto M (2002) Differential expression of disease resistance in rice lesion-mimic mutants. Plant Cell Rep 21(4):390-396. https://doi.org/10.1007/s00299-0020525-1

Mori M, Tomita C, Sugimoto K, Hasegawa M, Hayashi N, Dubouzet JG, Ochiai H, Sekimoto H, Hirochika H, Kikuchi S (2007) Isolation and molecular characterization of a Spotted leaf 18 mutant by modified activation-tagging in rice. Plant Mol Biol 63(6):847-860. https://doi.org/10.1007/s11103-006-913 $0-\mathrm{y}$

Nguyen QN, Lee YS, Cho LH, Jeong HJ, An G, Jung KH (2015) Genome-wide identification and analysis of Catharanthus roseus RLK1-like kinases in rice. Planta 241(3):603-613. https://doi.org/10.1007/s00425-014-2203-2 
Park CJ, Ronald PC (2012) Cleavage and nuclear localization of the rice XA21 immune receptor. Nat Commun 3(1):920 https://doi.org/10.1038/ncomms1 932

Park S, Moon JC, Park YC, Kim JH, Kim DS, Jang CS (2014) Molecular dissection of the response of a rice leucine-rich repeat receptor-like kinase (LRR-RLK) gene to abiotic stresses. J Plant Physiol 171(17):1645-1653. https://doi.org/10.1016/ j.jplph.2014.08.002

Petrov V, Hille J, Mueller-Roeber B, Gechev TS (2015) ROS-mediated abiotic stressinduced programmed cell death in plants. Front Plant Sci 6:69 https://doi. org/10.3389/fpls.2015.00069

Song D, Chen J, Song F, Zheng Z (2006) A novel rice MAPK gene, OsBIMK2, is involved in disease-resistance responses. Plant Biol (Stuttg) 8(5):587-596. https://doi.org/10.1055/s-2006-924149

Song WY, Wang GL, Chen LL, Kim HS, Pi LY, Holsten T, Gardner J, Wang B, Zhai WX, Zhu LH, Fauquet C, Ronald P (1995) A receptor kinase-like protein encoded by the rice disease resistance gene, Xa21. Science 270(5243):18041806. https://doi.org/10.1126/science.270.5243.1804

Takahashi A, Kawasaki T, Henmi K, Shil K, Kodama O, Satoh H, Shimamoto K (1999) Lesion mimic mutants of rice with alterations in early signaling events of defense. Plant J 17(5):535-545. https://doi.org/10.1046/j.1365-313X.1999. 00405.x

Tang J, Zhu X, Wang Y, Liu L, Xu B, Li F, Fang J, Chu C (2011) Semi-dominant mutations in the CC-NB-LRR-type $R$ gene, NLS1, lead to constitutive activation of defense responses in rice. Plant J 66(6):996-1007. https://doi. org/10.1111/j.1365-313X.2011.04557.X

Thomas CM, Dixon MS, Parniske M, Golstein C, Jones JD (1998) Genetic and molecular analysis of tomato $\mathrm{Cf}$ genes for resistance to Cladosporium fulvum. Philos Trans R Soc Lond Ser B Biol Sci 353(1374):1413-1424. https://doi.org/1 0.1098/rstb.1998.0296

Tian X, Li X, Zhou W, Ren Y, Wang Z, Liu Z, Tang J, Tong H, Fang J, Bu Q (2017) Transcription factor OsWRKY53 positively regulates Brassinosteroid signaling and plant architecture. Plant Physiol 175(3):1337-1349. https://doi.org/10.11 04/pp.17.00946

Walker JC (1994) Structure and function of the receptor-like protein kinases of higher plants. Plant Mol Biol 26(5):1599-1609. https://doi.org/10.1007/BF0001 6492

Wu C, Bordeos A, Madamba MR, Baraoidan M, Ramos M, Wang GL, Leach JE, Leung H (2008) Rice lesion mimic mutants with enhanced resistance to diseases. Mol Gen Genomics 279(6):605-619. https://doi.org/10.1007/s00438008-0337-2

Wu SW, Kumar R, Iswanto A, Kim JY (2018) Callose balancing at plasmodesmata. J Exp Bot 69(22):5325-5339. https://doi.org/10.1093/jxb/ery317

Yamanouchi U, Yano M, Lin H, Ashikari M, Yamada K (2002) A rice spotted leaf gene, Spl7, encodes a heat stress transcription factor protein. Proc Natl Acad Sci U S A 99(11):7530-7535. https://doi.org/10.1073/pnas.112209199

Yang L, Wu K, Gao P, Liu X, Li G, Wu Z (2014) GsLRPK, a novel cold-activated leucine-rich repeat receptor-like protein kinase from Glycine soja, is a positive regulator to cold stress tolerance. Plant Sci 215-216:19-28. https://doi.org/1 0.1016/j.plantsci.2013.10.009

Ye Y, Ding Y, Jiang Q, Wang F, Sun J, Zhu C (2017) The role of receptor-like protein kinases (RLKs) in abiotic stress response in plants. Plant Cell Rep 36(2): 235-242. https://doi.org/10.1007/s00299-016-2084-x

Yoshimura A, Ideta O, Iwata N (1997) Linkage map of phenotype and RFLP markers in rice. Plant Mol Biol 35(1-2):49-60. https://doi.org/10.1023/A:1 005764026871

Zeng L, Yin Z, Chen J, Leung H, Wang GL (2002) Fine genetic mapping and physical delimitation of the lesion mimic gene Spl11 to a 160-kb DNA segment of the rice genome. Mol Gen Genomics 268(2):253-261. https://doi. org/10.1007/s00438-002-0743-9

Zeng LR, Qu S, Bordeos A, Yang C, Baraoidan M, Yan H, Xie Q, Nahm BH, Leung H, Wang GL (2004) Spotted leaf11, a negative regulator of plant cell death and defense, encodes a U-box/armadillo repeat protein endowed with E3 ubiquitin ligase activity. Plant Cell 16(10):2795-2808. https://doi.org/10.1105/ tpc.104.025171

Zhang XR (1998) Leucine-rich repeat receptor-like kinases in plants. Plant Mol Biol Rep 16(4):301-311. https://doi.org/10.1023/A:1007540610933

\section{Publisher's Note}

Springer Nature remains neutral with regard to jurisdictional claims in published maps and institutional affiliations.

\section{Submit your manuscript to a SpringerOpen ${ }^{\circ}$ journal and benefit from:}

- Convenient online submission

- Rigorous peer review

- Open access: articles freely available online

High visibility within the field

- Retaining the copyright to your article

Submit your next manuscript at $\boldsymbol{\nabla}$ springeropen.com 